\title{
PENGARUH PROMOSI PENJUALAN DAN E-SERVICE QUALITY TERHADAP KEPUTUSAN PENGGUNAAN APLIKASI OVO
}

\author{
Amalia Fajrin \\ Fakultas Ekonomi Universitas Negeri Surabaya \\ Email: amaliafajrin@mhs.unesa.ac.id
}

\begin{abstract}
ABSTRAK
Peningkatan popularitas e-commerce berkembang sudah sampai ke tahap "berbelanja tanpa uang" dan kini budaya pembayaran menggunakan kartu atau dompet digital (cashless) untuk melakukan transaksi semakin marak terjadi. Riset McKinsey menyebutkan perkembangan layanan perbankan sedang bergeser ke layanan digital, akhir-akhir ini muncul fenomena maraknya penyedia uang elektronik di Indonesia dengan berbagai keunggulan. Maka, perusahaan e-payment harus mampu menyiapkan strategi dalam memasarkan produk agar tetap bersaing. Tujuan dari penelitian ini adalah menganalisis dan membahas pengaruh promosi penjualan dan e-service quality terhadap keputusan penggunaan Aplikasi OVO. Teknik pengambilan sampel yang digunakan adalah non probability sampling dengan metode jugmental sampling. Sampel yang digunakan sebanyak 200 orang. Responden dalam penelitian ini adalah konsumen yang telah melakukan transaksi di restoran/cafe merchantnya OVO, dengan minimal 2 kali transaksi dalam 1 bulan terakhir dan usia responden 20-39 tahun. Skala pengukuran menggunakan skala likert. Alat ukur yang digunakan adalah angket online. Teknik pengumpulan datamenggunakan kuesioner yang telah diuji validitas dan reliabilitasnya. Analisis data dengan menggunakan model persamaan regresi linier berganda. Hasil penelitian menunjukkan bahwa promosi penjualan berpengaruh positif terhadap keputusan penggunaan, dan EService Quality berpengaruh positif terhadap keputusan penggunaan. Hasil penelitian ini akan dapat membantu OVO dalam mempertahankan strategi promosi yang sudah dilakukan dan untuk terus meningkatkan e-service quality aplikasi OVO agar dapat memberikan layanan yang diharapkan penggunanya.
\end{abstract}

Kata Kunci: Promosi Penjualan, E-Service Quality, Keputusan Pembelian 


\section{PENDAHULUAN}

Perkembangan teknologi memberikan banyak kemudahan, serta sebagai cara baru dalam melakukan aktivitas manusia. Perkembangan terknologi sangat berkembang pesat, dengan internet kita tidak hanya mendekatkan yang jauh, mengetahui informasi secepat kilat, tapi sudah sampai ke tahap "Berbelanja Tanpa Uang". Bahkan pengguna internet di Indonesia dari tahun ke tahun mengalami peningkatan, diperkirakan mencapai angka hingga 175 juta pada tahun 2019, atau sekitar 65,3\% dari total penduduk Indonesia 268 juta. Maka dari itu trend pembayaran secara digital sudah mulai familiar saat ini. Peningkatan popularitas perdagangan secara online (e-commerce) di Indonesia mengubah gaya hidup masyarakat, termasuk dalam sistem pembayaran. Hal ini membuka peluang layanan keuangan berbasis teknologi atau financial technology (fintech) dalam membesarkan jangkauan usaha dan pasarnya. Fintech mempermudah transaksi jual beli sehingga system pembayaran menjadi lebih efisien dan ekonomis namun tetap efektif. Berdasarkan data dari Bank Indonesia (November 2018), volume transaksi terus meningkat hingga tahun 2018 mencapai nilai transaksi sebesar Rp41.312.466.

Kini budaya pembayaran menggunakan kartu atau dompet digital (cashless) semakin marak terjadi di Indonesia sehingga berdampak pada masyarakat yang tidak lagi menggunakan uang tunai dalam pembayaran atau bisa disebut dengan cashless society. Riset McKinsey menyebutkan bahwa saat ini layanan perbankan sedang bergeser ke digital bahkan nasabah juga mulai memindahkan saldo mereka hingga 50\% ke layanan digital. Berdasarakan hasil studi lembaga riset independen dibawah naungan Financial Times, FT Confidential Research Mobile Payment, penyedia uang elektronik yang paling banyak digunakan di Indonesia yaitu terdapat lima besar penyedia uang elektronik di Indonesia 2018. Diantaranya Go-Pay (2014), OVO (2017), Tcash (2014), BCA KlikPay (2012), dan DOKU Wallet (2007). Hasil riset menunjukkan bahwa Go-Pay menduduki peringkat pertama dengan jumlah pengguna yang mencapai tiga perempat dalam tiga bulan terakhir (juli-september) dari jumlah pengguna uang elektronik lainnya, diikuti oleh OVO yang naik sedikit sekitar 42 persen. Berdasarkan data dari media dalam negeri, Daily Social Fintech Report 2018 yang melakukan survey pengguna mobile payment di Indonesia 
menemukan persentase pengguna mobile payment yaitu Go-Pay (79\%), OVO (58,42\%), TCash $(55,52 \%)$, DANA $(34,18 \%)$, Pay Tren $(19,27 \%)$, Other $(0,97 \%)$, dan Not using EMoney $(3,70 \%)$. Pengguna Go-Pay menjadi yang teratas sampai saat ini, sedangkan pengguna OVO mempunyai selisih sedikit dengan Go-Pay. Perang akuisisi pelanggan antara Gopay (yang didukung Gojek) dan OVO (yang didukung Grab dan Tokopedia). Persaingan antara kedua pihak tersebut untuk memperebutkan para pelanggan. Konsumen di Indonesia memanfaatkan kompetisi ini dengan mengambil kesempatan promosi yang ditawarkan oleh Gopay dan OVO.

Promosi penjualan yang ditawarkan OVO seringkali dengan cashback yang besar hingga mencapai cashback $60 \%$ dan juga diskon yang menggiurkan hingga $50 \%$. Tetapi dengan maksimum cashback antara Rp20.000 - Rp30.000 sehingga konsumen terkadang tidak memperhatikan hal tersebut dan hanya melihat angka besar promosi penjualan yang ditawarkan OVO. Berdasarkan keluhan pengguna di sosmed Instagram OVO_id menunjukkan promosi penjualan OVO tidak konsisten karena sering konsumen tidak merasakan cashback yang ditawarkan dan tidak mendapatkan cashback tersebut. Hal tersebut membuat OVO sebagai mobile payment yang baru masih harus berupaya untuk meningkatkan kepercayaan konsumen terhadap OVO dengan memperbaiki segala yang jadi keluhan penggunanya. Saat ini yang dikeluhkan pengguna OVO yakni apa yang seharusnya dirasakan pelanggan tidak terjadi dengan semestinya. Beberapa layanan yang diberikan oleh OVO tidak berjalan dengan seharusnya sehingga terdapat banyak pelanggan yang komplain akan hal itu. Beberapa hal yang dialami oleh pengguna OVO yaitu pembobolan akun pengguna dengan PIN, transaksi error dan saldo yang hilang. Hal itu terjadi dikarenakan keamanan yang diberikan OVO belum terjamin dan layanan yang terdapat pada Aplikasi tidak berjalan sesuai dengan kegunaannya.

Berdasarkan katadata, $86 \%$ responden mengenal GoPay dan OVO, survey dilakukan pada 727 pengguna financial technologi jenis pembayaran dan memiliki pendapatan menengah ke atas di beberapa kota di Indonesia pada oktober 2018. Survei Morgan Stanley mengenai OVO dan GoPay menemukan bahwa perolehan bentuk Cashback yang berbeda yakni Cashback OVO berupa OVO Point sedangkan Cashback Go-Pay berupa uang kembali, dan untuk penggunaan (Use Case) OVO (73\%) dan Go-Pay 
(71\%) dengan persentase yang sangat bersaing, serta dana mengendap (Floating Fund) masing-masing sebesar OVO (minimal Rp 215.000) dan Go-Pay (minimal Rp 269.000). Pada Survey Jakpat Report 2018 produk yang diharapkan konsumen untuk dibeli menggunakan OVO dengan survey responden sebanyak 438 orang menghasilkan bahwa sebagian besar responden berharap dapat membeli makanan, elektronik \& gadget, dan fashion \& aksesoris menggunakan OVO. Selain itu, responden pria dalam survei ini juga berharap untuk membeli bahan bakar dan penarikan. Sedangkan responden perempuan berharap dapat membayar parkir dan membeli bahan makanan menggunakan OVO. Mayoritas responden ovo (60\%) pengguna berharap menggunakan transaksi untuk makan di restoran/cafe. Merchant-merchant yang dimiliki OVO sebanyak 500.000 merchant dengan diunduh 115 sedangkan Go-Pay memiliki lebih sedikit merchant yakni 200.000 merchant dengan diunduh 105 juta. OVO telah mencatatkan pertumbuhan jumlah merchant lebih dari 70\% di tahun 2018. Berbagai macam layanan yang ditawarkan OVO juga sangat lengkap, meliputi Onsite Dining, Offline Retail, Offline Groceries, Online Marketplace, Food Delivery, Online Transportation, Telecom Top-Ups, Utilities, Investment, dan Fund transfer.

Dengan latar belakang tersebut, maka peneliti tertarik untuk mengambil judul "Pengaruh Promosi Penjualan dan E-Service Quality Terhadap Keputusan Penggunaan OVO. Karena OVO merupakan e-money pendatang baru yang gencar melakukan promosi di berbagai merchant-merchantnya tetapi terdapat beberapa promosi yang memang tidak benar-benar dirasakan langsung oleh penggunanya dan E-Service Quality yang terdapat dalam aplikasi OVO keamanannya belum maksimal yang dapat meresahkan pengguna. Namun OVO mampu menarik banyak konsumen untuk mencoba menggunakan aplikasi OVO berdasarkan jumlah pengguna yang dimilikinya yang menyaingi e-payment yang sudah lama muncul.

\section{Rumusan Masalah}

Berdasarkan latar belakang masalah yang telah diuraikan sebelumnya, maka dapat dirumuskan dua persoalan penelitian sebagai berikut: 1). Adakah pengaruh promosi penjualan terhadap keputusan penggunaan Aplikasi OVO. 2). Adakah pengaruh EService Quality terhadap keputusan penggunaan Aplikasi OVO? 
http://doi.org/10.21009/JRMSI

\section{Tujuan Penelitian}

Tujuan penelitian merupakan jawaban atau saran yang ingin dicapai penulis dalam sebuah penelitian. Oleh sebab itu, tujuan penelitian ini adalah: 1). Untuk menganalisis dan membahas pengaruh promosi penjualan terhadap keputusan penggunaan Aplikasi OVO 2). Untuk menganalisis dan membahas pengaruh promosi penjualan terhadap keputusan penggunaan Aplikasi OVO

\section{TELAAH PUSTAKA}

Perkembangan pesat sebuah teknologi mampu menggeser pola pikir masyarakat untuk bisa mendapatkan kebutuhannya secara praktis dan mudah. Hal tersebut membuat pemasar untuk terus memahami perilaku konsumen yang mulai banyak beralih ke online untuk memenuhi kebutuhan dengan mudah. Turban et al. (2015:407), mengemukakan bahwa perilaku konsumen dalam perdagangan elektronik atau e-commerce meliputi proses pembelian, penjualan, transfer, atau pertukaran produk, layanan atau informasi melalui jaringan internet. Perilaku konsumen online memiliki lima faktor menurut Turban et al. (2015:408-409) yaitu Consumer Characteristics, Merchant and Intermediary-Related Factors, Product/Service Factors, Environmental Factors, dan system e-commerce. Transaksi online juga bisa dipengaruhi oleh merchant atau penyedia produk dan jasa. Kelompok faktor ini mencakup reputasi pedagang, ukuran transaksi, kepercayaan pada merchant, dan sebagainya.

Dalam Merchant and Intermediary-Related Factors terdapat faktor lain seperti strategi pemasaran dan iklan juga dapat memainkan peran utama. Pencarian konsumen untuk informasi, katalog, iklan, promosi, dan kelompok referensi dapat memengaruhi pengambilan keputusan. Pelanggan dapat memanfaatkan penawaran dan promosi online khusus dan memanfaatkan peluang untuk mencoba produk atau layanan baru dengan tujuan yakni membangun kesadaran merek, mengubah citra merek, promosi penjualan, meningkatkan loyalitas merek, membangun database pelanggan, dan merangsang mobile WOM. Umumnya, perusahaan menggunakan promosi penjualan sebagai suatu stimulus untuk mendorong penjualan dengan cepat. Blythe (2005) yang menggambarkan bahwa promosi penjualan memainkan peran penting dalam membangun kesadaran merek yang 
nantinya dapat menghasilkan keputusan pembelian. Sebagian besar studi menyimpulkan bahwa promosi penjualan dapat secara signifikan berdampak pada perilaku konsumen dan keputusan pembelian mereka, meskipun efek dari berbagai komponennya mungkin berbeda (Neslin, 2002).

Alat-alat sales promotion menurut Kotler, Bowen, \& Makens (2014:417) terdapat sembilan macam, yaitu samples, coupons or voucher, premiums, patronage rewards, discount, bonus packs, rebates (penawaran cashback), point of purchase, dan contest, sweepstakes, and games. Dalam penelitian ini indikator promosi penjualan yang digunakan menurut Razati (2008), Hulya Bakırtas (2013), Natalia \& Mulyana (2014), dan Nagadeepa et al. (2015) yaitu 1) Rebate (Caschback), Penawaran pengembalian tunai dengan item, a) Menawarkan penurunan harga yang diterima oleh pelanggan setelah pembelian dilakukan, b) Rabat (Cashback) menarik perhatian konsumen, b) Rabat (Cashback) mempengaruhi keputusan pembelian, 2) Discount (Diskon), Potongan harga secara langsung dengan item, a) Paket layanan yang ditawarkannya sangat menentukan bagi saya, $b$ ) Diskon mendorong untuk melakukan pembelian, c) Tingkat besarnya diskon yang diberikan kepada konsumen, 3) Coupon (Voucher), Hak potongan yang diberikan kepada pemegang voucher dengan item, a) Pemegang voucher mendapatkan diskon pada produk tertentu, $b$ )Promosi kupon mempengaruhi volume produk yang dibeli, 4) Price Packs (Paket Harga), Produk dibundel bersama dengan harga satu atau dengan harga diskon seperti beli dua gratis satu, a) Memberikan skema pengurangan harga kepada konsumen yang ditandai langsung pada paket dua atau lebih produk, $b$ ) Paket harga menstimuli keputusan pembelian konsumen H1 : Ada pengaruh antara Promosi penjualan terhadap keputusan penggunaan Aplikasi OVO

Dalam konteks internet, kualitas layanan elektronik didefinisikan sebagai evaluasi dan penilaian menyeluruh konsumen terhadap kualitas pengiriman e-service di pasar internet (Santos, 2003). A.Parasuraman, Valarie A.Zeithaml, Malhotra (2005) mengartikan e-service quality sebagai sejauh mana sebuah website mempu memfasilitasi kegiatan konsumen meliputi belanja, pembelian, dan pengiriman baik produk atau layanan secara efisien dan efektif.Kualitas layanan meliputi harapan pelanggan dan persepsi pelanggan terhadap layanan tersebut serta diukur oleh apa yang dirasakan pelanggan. Kualitas 
layanan telah menjadi masalah penting dalam domain e-commerce untuk mengukur keberhasilan e-commerce (Delone \& McLean, 2004).

A.Parasuraman, Valarie A.Zeithaml, dan Malhotra (2002) mengembangkan lima dimensi dari e-service quality lainnya, yaitu: Information availability and content, Ease of use (usability), Privacy (security), Graphic style, dan Fullfilment. Sedangkan A.Parasuraman, Valarie A.Zeithaml, dan Malhotra (2005) mengembangkan empat dimensi dari e-service quality lainnya, yaitu: Efficiency, Fulfillment, System availability, dan Privacy. Indikator E-Service Quality yang digunakan dalam penelitian ini adalah menurut Wolfinbarger \& Gilly (2003), Parasuraman, Valarie A.Zeithaml (2005), Rolland \& Freeman (2010), Sheng (2010), Beheshti et al. (2012), Charles k. Ayo Aderonke (2016) yaitu 1) System Availability (Ketersediaan Sistem), Fungsi teknis sistem yang sesuai dengan item a) Situs ini tidak crash, b) Situs ini selalu tersedia untuk bisnis, c) Ketersediaan solusi e-banking dan kemampuan berjalan lancar saat memproses transaksi, 2) Fulfilment (Pemenuhan), Tingkat ketepatan penggambaran produk pada website, tingkat akurasi dalam memproses pesanan dengan item, a) Transaksi internet banking selalu akurat, b) Bagian internet banking dari situs web diluncurkan dan dijalankan segera, c) Janji yang akurat tentang layanan yang disampaikan, 3) Privacy (Privasi), Perlindungan yang diberikan kepada konsumen dari risiko penipuan dan kerugian finansial dari penggunaan informasi keuangannya dengan item, a) Saya merasa aman dalam transaksi saya dengan situs web ini, b) Situs ini tidak akan membagikan informasi pribadi saya dengan situs lain, $c$ ) Situs ini akan melindungi informasi kartu bank saya dan pembayaran online saya, 4) Efficiency (Efisiensi), Kemudahan dan kecepatan mengakses dan menggunakan situs dengan item, a) Saya dapat dengan mudah menemukan apa yang saya butuhkan di situs ini dengan beberapa klik, b) Ini memungkinkan saya untuk menyelesaikan transaksi dengan cepat, c) Situs ini memungkinkan saya untuk melanjutkan penggunaan saya dengan mudah, 5) Ease of use (kemudahan penggunaan), Fungsi pencarian, kecepatan download, desain, dan tata letak sebuah website yang dirasakan oleh konsumen dengan item, a) Mampu menggunakan utilitas situs web internet perbankan tanpa banyak usaha, b) Kemudahan bergerak di antara halaman, c) Kemudahan navigasi dalam suatu halaman. 
H2 : Ada pengaruh antara E-Service Quality terhadap keputusan penggunaan Aplikasi OVO

Keputusan pembelian online yaitu proses alternatif yang mengkombinasikan pengetahuan untuk mengevaluasi dua atau lebih perilaku alternative, dan memilih salah satu diantaranya yang kuat hubungannya dengan karakter personal, vendor/service, website quality, sikap pada saat pembelian, maksud untuk membeli online, dan pengambilan keputusan (Mahkota dkk, 2014). Indikator keputusan penggunaan yang digunakan dalam penelitian ini adalah merujuk dari (Childers, Carr, Peck, \& Carson, 2001),(Kim, Ferrin, \& Rao, 2008), (Karimi, Papamichail, \& Holland, 2015), dan (Penia Anggraeni \& Putu Nina, 2016) yaitu 1) Manfaat, Manfaat yang dirasakan (MANFAAT) sebagai keyakinan konsumen tentang sejauh mana ia akan menjadi lebih baik dari transaksi online dengan Situs web tertentu dengan item, a) Saya dapat menghemat uang dengan menggunakan situs web ini, b) Saya dapat menghemat waktu dengan menggunakan situs web ini, 2) Kualitas Informasi, Persepsi umum konsumen tentang akurasi dan kelengkapan informasi situs web yang berkaitan dengan produk dan transaksi dengan item, a) Situs web ini memberikan informasi yang benar tentang barang yang ingin saya beli, b) Situs web menyediakan informasi yang cukup ketika saya mencoba melakukan transaksi 3) Keamanan, Konsumen merasakan perlindungan keamanan ketika melakukan transaksi online tergantung pada seberapa jelas dia memahami tingkat tindakan keamanan yang diterapkan oleh penjual dengan item a) Vendor web ini menerapkan langkah-langkah keamanan untuk melindungi pembeli di internet, b) Saya merasa aman dalam melakukan transaksi di situs web ini, 4) Interaksi , Interaksi (timbal balik) dalam proses keputusan dengan item, a) Lambat waktu dalam memuat (loadtime), b) Petunjuk/navigasi dalam mengeksplorasi alternatif untuk mencari informasi terkait produk, 5) Efisiensi, Efisiensi untuk pencarian dalam situs dengan item, a) Kecepatan waktu dalam pencarian, b) kemudahan dalam penggunaan. 


\section{MODEL PENELITIAN}

Rancangan penelitian yang digunakan adalah riset konklusif dengan pendekatan kausal. Jenis dan sumber data yang digunakan dalam penelitian ini adalah Data primer pada penelitian ini berupa jawaban responden yang didapat dengan menyebar angket online pada responden melalui Google Form.

\section{Populasi}

Populasi dalam penelitian ini adalah pengguna aktif yang melakukan transaksi menggunakan Aplikasi OVO di restoran/cafe merchantnya OVO, adapun karakteristik populasi yaitu Usia pengguna antara 20-39 tahun dan Responden merupakan pengguna aplikasi OVO yang telah melakukan transaksi di restoran/cafe merchantnya OVO minimal 2x dalam 1 bulan terakhir. Populasi dalam penelitian ini bersifat infinite artinya jumlah populasi yang diteliti tidak diketahui.

\section{Sampel}

Metode penentuan sampel dalam penelitian ini yaitu non probability sampling menggunakan judgmental sampling. Pada penelitian ini ukuran sampel minimum pada studi pengujian pasar adalah sebesar 200 responden Malhotra (2009:369). Penelitian ini dilakukan secara online khusus pada pengguna OVO yang melakukan transaksi di restoran/cafe merchantnya OVO. Media online yang digunakan yaitu sosmed pada Instagram, Line, Facebook, dan Whatsapp. Skala pengukuran yang digunakan dalam penelitian ini adalah skala likert.

Skala likert merupakan skala pengukuran dengan lima kategori respon yang berkisar antara "sangat setuju" hinggga "sangat tidak setuju" yang mengharuskan responden menentukan derajat persetujuan atau ketidak setujuan mereka terhadap masing-masing dari serangkaian pernyataan mengenai objek stimulus (Malhotra, 2009:298). Skala Likert yang digunakan adalah dengan menggunakan 5 skala atau tingkatan.

- Nilai 5 untuk responden yang menjawab sangat setuju

- Nilai 4 untuk responden yang menjawab setuju

- Nilai 3 untuk responden yang menjawab ragu-ragu

- Nilai 2 untuk responden yang menjawab tidak setuju 
- Nilai 1 untuk responden yang menjawab sangat tidak setuju

Proses pengumpulan data dilakukan secara online dengan tahap yakni peneliti membuat angket menggunakan google form, mencari responden secara judgmental yang sesuai dengan kriteria penelitian, Peneliti memberikan link angket online melalui beberapa media sosial seperti instagram, whatsapp, line, dan facebook yaitu http://bit.ly/skripsiamelovounesa, Hasil jawaban responden masuk ke database email peneliti, dan Peneliti menganalisis dan mengolah data yang telah masuk ke database.

\section{Analisis Data}

Data dianalisis menggunakan analisis regresi linear berganda (Multiple Linear Regression Analysis). Model regresi linier berganda dapat dikatakan baik jika model tersebut dapat memenuhi syarat asumsi normalitas data dan terbatas dari asumsi klasik statistic baik multikolineritas dan heteroskedastisitas. Pengujian asumsi tersebut meliputi: uji normalitas, uji multikolinieritas, dan uji heteroskedastisitas.

\section{HASIL DAN PEMBAHASAN}

\section{Karakteristik Responden}

Dalam penelitian ini karakteristik responden dapat didefinisikan melalui faktor usia, jenis kelamin, pekerjaan, pengeluaran, frekuensi transaksi, dan waktu transaksi.

Tabel 1 Karakteristik Responden

\begin{tabular}{cccc}
\hline Karakteristik Responden & Jumlah & $\begin{array}{c}\text { Persentase } \\
(\boldsymbol{\%})\end{array}$ \\
\hline Usia & $20-25$ & 158 & $79 \%$ \\
Responden & $26-31$ & 28 & $14 \%$ \\
& $32-39$ & 14 & $7 \%$ \\
Jenis & Total & 200 & 100 \\
Kelamin & Laki-Laki & 74 & $37 \%$ \\
& Perempuan & 126 & $63 \%$ \\
& Total & 200 & 100 \\
Pekerjaan & Pelajar & 1 & $0,5 \%$ \\
& Mahasiswa & 110 & $55 \%$ \\
& Pary & 7 & $3,5 \%$ \\
& Kawan Swasta & 50 & $25 \%$ \\
Pengeluaran & Lainnya & 32 & $16 \%$ \\
Selama & Total $\quad$ Rp 1.000.000 & 200 & 100 \\
1 bulan & Rp 1.000.000- & 61 & $30,5 \%$ \\
& Rp 3.000.000 & 104 & $52 \%$ \\
& & &
\end{tabular}




\begin{tabular}{|c|c|c|c|}
\hline & $\begin{array}{l}\quad>\operatorname{Rp} 3.000 .000 \\
\text { Total }\end{array}$ & $\begin{array}{c}35 \\
200\end{array}$ & $\begin{array}{c}17,5 \% \\
100\end{array}$ \\
\hline Frekuensi & 2 kali & 56 & $28 \%$ \\
\hline \multicolumn{4}{|l|}{ Transaksi } \\
\hline \multirow[t]{2}{*}{ OVO } & $>2$ kali & 144 & $72 \%$ \\
\hline & Total & 200 & 100 \\
\hline \multirow{2}{*}{\multicolumn{4}{|c|}{$\begin{array}{l}\text { Waktu } \\
\text { Transaksi }\end{array}$}} \\
\hline & & & \\
\hline \multirow[t]{2}{*}{ OVO } & $>1$ bulan terakhir & 0 & $0 \%$ \\
\hline & Total & 200 & 100 \\
\hline
\end{tabular}

Sumber : Data primer diolah peneliti

Berdasarkan tabel di atas, terlihat bahwa responden didominasi usia 20-25 tahun sejumlah 158 responden dengan jenis mayoritas berjenis kelamin perempuan sebagai mahasiswa dengan persentase $55 \%$ dan pengeluaran selama 1 bulan paling banyak yaitu Rp 1.000.000 - Rp 3.000.000 yang melakukan transaksi pada merchant OVO pada restoran maupun cafe lebih dari 2 kali dalam waktu 1 bulan terakhir.

\section{Hasil Pengujian Data}

\section{Uji Validitas}

Uji validitas dilakukan dengan menyebar angket online kepada 30 responden untuk mengetahui seberapa mampu kuesioner dapat mengungkapkan pernyataan variabel yang diukur. Responden sejumlah 30 orang ini tidak termasuk dalam 200 responden untuk mengukur kualitas angket yang akan disebar pada jumlah sampel yang telah ditentukan. Suatu pernyataan dikatakan valid jika nilai $r$-hitung $>0,30$. Jadi apabila suatu pernyataan memiliki nilai $r$ - hitung dibawah 0,30 maka dikatakan tidak valid. Berdasarkan perhitungan menggunakan SPSS 18 for windows diperoleh hasil uji validitas sebagai berikut :

\section{Tabel 2 Uji Validitas}

\begin{tabular}{lccc}
\hline Variabel & $\begin{array}{c}\text { Corrected Item- } \\
\text { Total Correlation }\end{array}$ & $\mathbf{r}_{\text {table }}$ & Ket. \\
\hline PROMOSI PENJUALAN $\left(\mathbf{X}_{\mathbf{1}}\right)$ & & \\
$\mathrm{X}_{1.1 .1}$ & 0,709 & & Valid \\
$\mathrm{X}_{1.1 .2}$ & 0,715 & & Valid \\
$\mathrm{X}_{1.1 .3}$ & 0,811 & 0,30 & Valid \\
$\mathrm{X}_{1.2 .1}$ & 0,763 & & Valid \\
$\mathrm{X}_{1.2 .2}$ & 0,850 & & Valid \\
$\mathrm{X}_{1.2 .3}$ & 0,767 & & Valid \\
$\mathrm{X}_{1.3 .1}$ & 0,638 & Valid \\
$\mathrm{X}_{1.3 .2}$ & 0,827 & & Valid \\
$\mathrm{X}_{1.4 .1}$ & 0,736 & & Valid
\end{tabular}


Jurnal Riset Manajemen Sains Indonesia (JRMSI) | Vol 11, No. 2, 2020 http://doi.org/10.21009/JRMSI

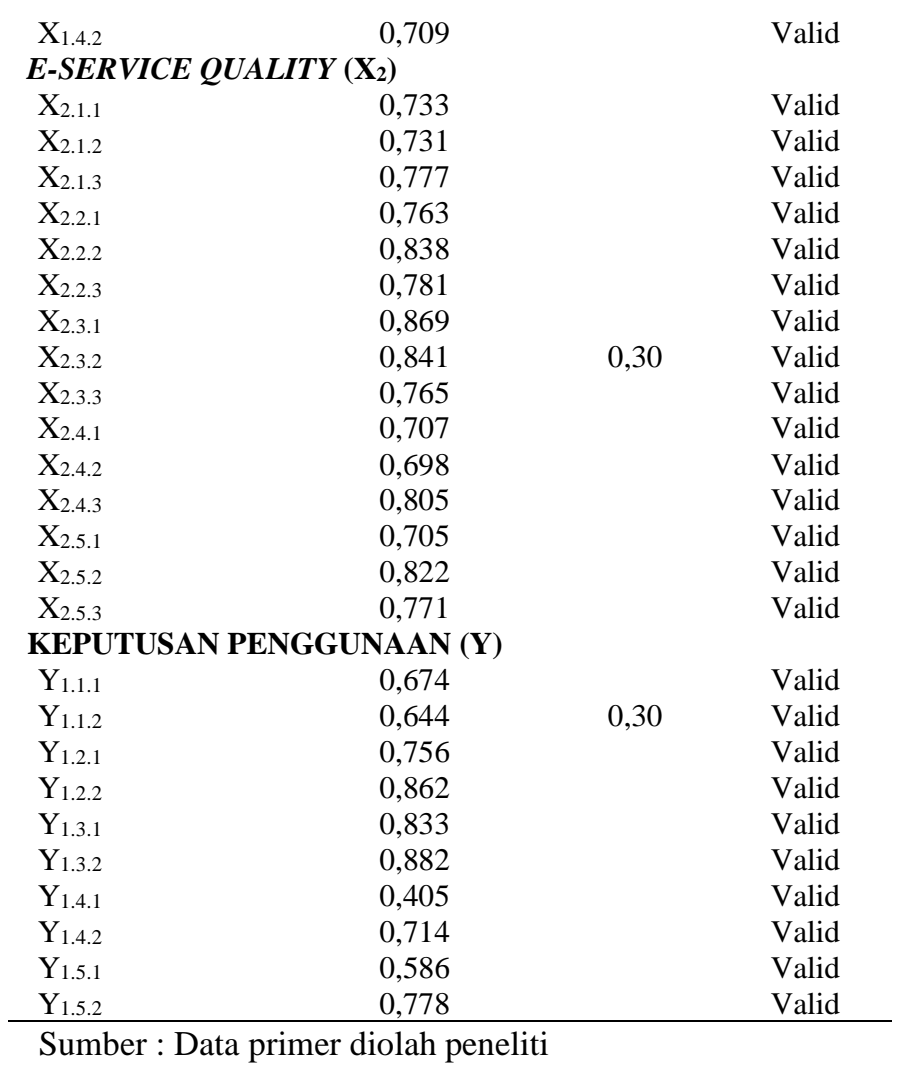

Berdasarkan tabel 2 diatas, dapat diketahui bahwa seluruh item pernyataan memiliki r-hitung $>0,30$ sehingga dapat disimpulkan bahwa pernyataan-pernyataan pada instrument penelitian (angket) dinyatakan valid dan dapat digunakan sebagai alat ukur pengaruh promosi penjualan dan e-service quality terhadap keputusan penggunaan.

\section{Uji Reliabilitas}

Setelah alat ukur telah dinyatakan valid, maka kemudian dilakukan pengukuran reliabilitas terhadap alat ukur tersebut terhadap 30 responden. Menurut Ghozali (2016:47) suatu kuesioner dikatakan reliable atau handal apabila jawaban responden terhadap pernyataan adalah konsisten atau stabil dari waktu ke waktu. Uji statistic Cronbach Alfa, di mana suatu variabel dikatakan reliable apabila nilai Cronbach Alpha > 0,70 (Ghozali, 2016:48). Berikut hasil uji reliabilitas instumen penelitian yang tercantum dalam tabel 3 sebagai berikut : 
Jurnal Riset Manajemen Sains Indonesia (JRMSI) | Vol 11, No. 2, 2020

e-ISSN: $2301-8313$

http://doi.org/10.21009/JRMSI

Tabel 3 Uji Reliabilitas

\begin{tabular}{llll}
\hline \multicolumn{1}{c}{ Variabel } & $\begin{array}{c}\text { Cronbach } \\
\text { Alpha }\end{array}$ & $\begin{array}{l}\text { Nilai } \\
\text { Kritis }\end{array}$ & Ket. \\
\hline Promosi Penjualan & 0,912 & & Reliabel \\
E-Service Quality & 0,950 & 0,70 & Reliabel \\
Keputusan Penggunaan & 0,887 & & Reliabel \\
\hline
\end{tabular}

Sumber : Data primer diolah peneliti

Berdasarkan tabel 3, dapat diketahui bahwa besarnya nilai Cronbach's Alpha untuk pengaruh promosi penjulan, e-service quality dan keputusan penggunaan lebih besar dari 0,70 sehingga dapat disimpulkan bahwa pernyataan-pernyataan pada instrument penelitian (angket) reliable dan dapat digunakan sebagai alat ukur pengaruh promosi penjualan dan $e$ service quality terhadap keputusan penggunaan.

\section{Uji Asumsi Klasik}

\section{Uji Normalitas}

Untuk menguji normalitas, peneliti menggunakan cara uji statistic non Parametic Kolmogrov-Smirnov (K-S), jika K-S jauh di atas a=0,05 maka data terdistribusi normal (Ghozali, 2016:158). Berikut hasil uji normalitas residual menggunakan Kolmogrov-Smirnov :

Tabel 4 Uji Normalitas Kolmogrov Smirnov

\begin{tabular}{|c|c|c|}
\hline \multicolumn{3}{|c|}{ One-Sample Kolmogorov-Smirnov Test } \\
\hline & & $\begin{array}{l}\text { Unstandardized } \\
\text { Residual }\end{array}$ \\
\hline $\mathrm{N}$ & & 200 \\
\hline \multirow[t]{2}{*}{ Normal Parameters ${ }^{\mathrm{a}, \mathrm{b}}$} & Mean &, 0000000 \\
\hline & Std. Deviation & 3,82214819 \\
\hline \multirow{3}{*}{$\begin{array}{l}\text { Most Extreme } \\
\text { Differences }\end{array}$} & Absolute &, 038 \\
\hline & Positive & 038 \\
\hline & Negative &,- 029 \\
\hline \multicolumn{2}{|l|}{ Kolmogorov-Smirnov Z } &, 537 \\
\hline \multicolumn{2}{|l|}{ Asymp. Sig. (2-tailed) } & ,935 \\
\hline \multicolumn{3}{|c|}{ a. Test distribution is Normal. } \\
\hline \multicolumn{3}{|l|}{ b. Calculated from data. } \\
\hline
\end{tabular}


Berdasarkan tabel 4 dapat dilihat pada analisis grafik, titik-titik normal probability plot P-P plot regresi menyebar disekitar garis diagonal, sementara pada uji statistic nilai signifikansi uji Kolmogrov Smirnov yaitu 0,935 yang lebih besar dari 0,05 maka dapat disimpulkan bahwa data tersebut berdistribusi normal.

\title{
Uji Multikorelasi
}

Uji multikolineritas dilakukan untuk menguji model regresi adakah korelasi antar variabel independen. Multikolineritas dapat dilihat dari nilai tolerance dan VIF (Variance Inflation Factors). Adanya multikolineritas ditunjukkan dengan nilai tolerance $\geq 0,01$ atau VIF $\leq 10$ (Ghozali, 2016:105). Berikut ini adalah hasil multikolinieritas :

Tabel 5 Uji Multikolinieritas

\begin{tabular}{llrr}
\multicolumn{4}{c}{ Coefficients $^{\mathbf{a}}$} \\
\hline Model & \multicolumn{2}{c}{ Collinearity } & Statistics \\
& & & \\
\hline 1 & (Constant) & & \multicolumn{1}{c}{ VIF } \\
& E_SERVICE_QUALITY &, 761 & 1,313 \\
& PROMOSI_PENJUALAN &, 761 & 1,313 \\
\hline
\end{tabular}

a. Dependent Variable: KEPUTUSAN_PENGGUNAAN

\author{
Sumber : Data primer diolah peneliti
}

Berdasarkan tabel 5 diketahui bahwa nilai tolerance kedua variabel yaitu 0,761<0,10 artinya tidak terjadi multikolinieritas antar variabel independen, begitu juga nilai VIF kedua variabel yaitu $1,313<10$ artinya tidak terjadi multikolinieritas antar variabel independent, dapat disimpulkan bahwa penelitian ini tidak terjadi korelasi yang kuat antar variabel independent, sehingga model regresi ini masih dapat ditoleransi.

\section{Uji Heteroskedastisitas}

Uji hereroskedastisitas bertujuan untuk menguji model regresi apakah terjadi ketidaksamaan variance dari residual satu pengamatan ke pengamatan yang lain. Model regresi yang baik yaitu yang tidak terjadi heteroskedastisitas (homoskedastisitas) 
(Ghozali, 2016:134). Cara untuk mendeteksi ada atau tidaknya heteroskedastisitas yaitu dengan melihat Grafik Plot antara nilai prediksi variabel terikat (dependen) yaitu ZPRED dengan residualnya SRESID. Dasar analisis :

1) Jika ada pola tertentu, seperti titik-titik yang membentuk pola tertentu yang teratur (bergelombang, melebar kemudian menyempit) maka mengindikasikan telah terjadi heteroskedastisitas.

2) Jika tidak ada pola yang jelas, serta titik-titik menyebar di atas dan di bawah angka 0 pada sumbu Y, maka tidak terjadi heteroskedastisitas (Ghozali, 2016:134).

Berikut adalah hasil grafik scatterplot dari uji heteroskedastisitas :

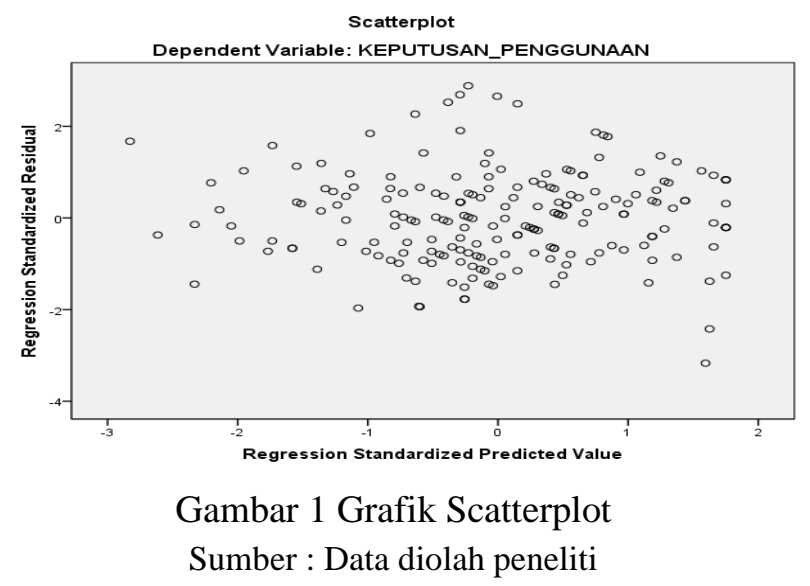

Berdasarkan gambar 1, dapat terlihat bahwa titik-titik menyebar secara acak serta tersebar baik di atas maupun di bawah angka 0 dan sumbu Y. Hal ini dapat disimpulkan bahwa tidak terjadi heteroskedastisitas pada model regresi, sehingga model regresi layak dipakai.

\section{Pengujian Hipotesis}

Setelah terbebas dari asumsi-asumsi klasik, kemudian dilakukan analisis regresi linier berganda. Hasil uji analisis regresi linier berganda dapat dilihat pada tabel di bawah ini : 
Tabel 6 Hasil Analisis Linier Berganda

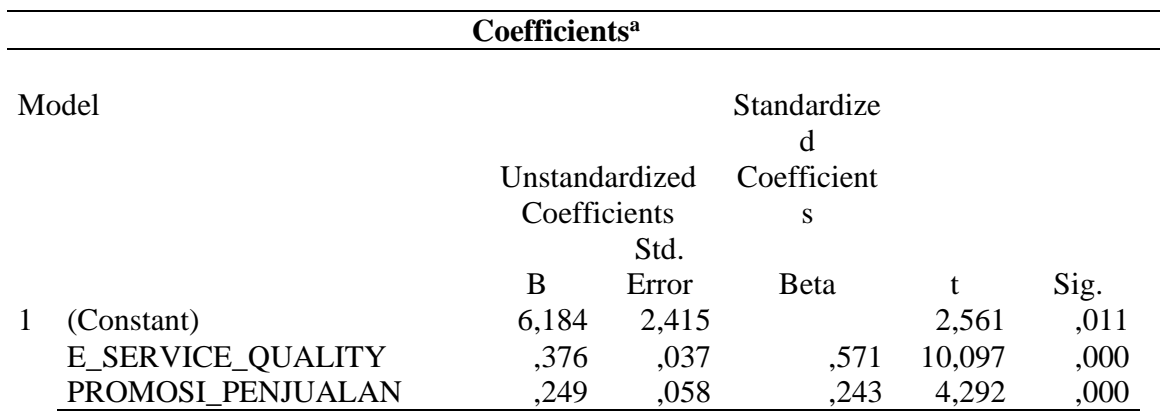

a. Dependent Variable: KEPUTUSAN_PENGGUNAAN

Sumber : Data primer diolah peneliti

Hipotesis pertama yang menyatakan ada pengaruh variabel promosi penjualan terhadap keputusan penggunaan Aplikasi OVO adalah diterima. Hal tersebut dapat dilihat dari nilai t hitung pada tabel tersebut yakni sebesar 4,292 dengan nilai signifikansi sebesar $0,000<0,05$. Hipotesis kedua yang menyatakan ada pengaruh e-service quality terhadap keputusan penggunaan Aplikasi OVO adalah diterima. Hal tersebut dapat dilihat dari nilai thitung pada tabel tersebut yakni sebesar 10,097 dengan nilai signifikansi sebesar 0,000 < 0,05. Adapun pengaruh paling besar terhadap keputusan penggunaan adalah dipengaruhi oleh e-service quality yakni sebesar 10,097. Uji pengaruh promosi penjualan dan E-Service Quality terhadap keputusan penggunaan Aplikasi OVO menghasilkan nilai R (korelasi) dan $\mathrm{R}^{2}$ (koefisien determinan) berikut dibawah ini :

Tabel 7 Hasil Uji Kelayakan Model

\begin{tabular}{lcrc}
\hline \multicolumn{3}{c}{ Model Summary $^{\mathbf{b}}$} \\
\hline Model & & \\
& $\mathrm{R}$ & R Square & $\begin{array}{c}\text { Adjusted R } \\
\text { Square }\end{array}$ \\
1 &, $721^{\text {a }}$ &, 520 &, 515 \\
& & \\
a. Predictors: (Constant), PROMOSI_PENJUALAN, \\
E_SERVICE_QUALITY
\end{tabular}

b. Dependent Variable: KEPUTUSAN_PENGGUNAAN

Sumber : Data primer diolah peneliti

Dari tabel $7 \mathrm{di}$ atas dapat diketahui besarnya kontribusi dari variabel promosi penjualan (X1) dan E-Service Quality (X2) terhadap Keputusan Penggunaan (Y). dapat 
dilihat bahwa nilai koefisien Adjusted R Square sebesar 0,515 (51,5\%). Sehingga nilai tersebut berarti bahwa model yang digunakan dapat menjelaskan variabel-variabel yang diteliti sebesar 51,5\%. Sedangkan sisanya yakni 48,5\% dijelaskan atau dipengaruhi oleh variabel lain di luar variabel yang diteliti dalam penelitian ini

\section{Pengaruh Promosi Penjualan Terhadap Keputusan Penggunaan Aplikasi OVO}

Berdasarkan hasil analisis regresi linier berganda, maka dapat diketahui bahwa promosi penjualan berpengaruh positif terhadap keputusan penggunaan. Penelitian ini sesuai dengan teori Efraim Turban (2015:408) mobile marketing dan kampanye periklanan memiliki empat kelas kampanye online yang terdapat enam tujuan yaitu membangun kesadaran merek, mengubah citra merek, promosi penjualan, meningkatkan loyalitas merek, membangun database pelanggan, dan merangsang mobile WOM.

Hasil penelitian ini mendukung penelitian oleh Jamaludin (2015) dan Darko (2012) yang menemukan bahwa promosi penjualan memiliki pengaruh signifikan terhadap keputusan pembelian online. Hulya Bakırtas (2013) dan Maftukhah, Rahmawati, \& Fadlilah (2018) dalam penelitiannya promosi penjualan memiliki dampak positif signifikan terhadap keputusan pembelian online. Promosi penjualan yang ditawarkan OVO sangat beragam dan promosi penjualan juga sering dilakukan guna menarik konsumen. Pada event-event tertentu OVO sering menawarkan cashback dan diskon yang besar seperti promo hore gajian, COBLOS (Cashback OVO buat Belanja Lancar Boss) dengan cashback $60 \%$ yang tersedia pada merchant-merchant OVO.

Cashback diberikan kepada pengguna OVO dalam bentuk OVO Point, OVO Point diperoleh dari pengembalian tunai berdasarkan harga yang harus dibayar dalam transaksi di restoran/cafe merchant OVO. OVO Point tersebut dapat digunakan kembali untuk transaksi pada merchant rekanan OVO. Diskon yang ditawarkan dengan ketentuan yang berlaku dapat dinikmati pengguna untuk mendapatkan menu-menu tertentu dengan harga spesial. Pengguna hanya perlu membeli voucher pada aplikasi OVO yang menyediakan diskon di restoran/cafe merchant OVO lalu menukarkannya di tempat yang telah ditentukan. Penawaran voucher untuk restoran/cafe pada aplikasi OVO memberikan voucher value sesuai ketentuan untuk dapat menikmati semua menu yang disajikan pada 
lokasi merchant tertentu. Pengguna dapat membeli voucher tersebut dengan harga yang lebih hemat untuk mendapatkan yang lebih. Paket harga pada restoran/cafe dengan set menu yang ditentukan untuk beberapa orang dapat dibeli pada aplikasi OVO. Sehingga pengguna mendapatkan harga yang lebih hemat untuk bisa menikmati paket menu hidangan yang ditawarkan.

Hasil statistik menunjukkan bahwa item pernyataan yang memperoleh nilai mean tertinggi adalah item pernyataan $\mathrm{X}_{1.1 .2}$ menyatakan "cashback menarik perhatian konsumen". Yang artinya pengguna OVO sangat setuju jika cashback yang ditawarkan OVO mampu menarik perhatian konsumen, maka pengguna akan tertarik melakukan transaksi menggunakan OVO saat banyak promosi-promosi cashback yang menggiurkan. Serta responden tidak akan melakukan penggunaan transaksi pada merchant OVO apabila tidak mengetahui cashback yang ditawarkan merchant-merchant tertentu.

\section{Pengaruh E-Service Quality Terhadap Keputusan Penggunaan Aplikasi OVO}

Berdasarkan hasil analisis regresi linier berganda, maka dapat diketahui bahwa E-Service Quality berpengaruh positif terhadap keputusan penggunaan Aplikasi OVO. Hal ini sesuai dengan teori menurut Efraim Turban (2015:409) keputusan pembelian online dipengaruhi oleh E-Service Quality. Kualitas layanan telah menjadi masalah penting dalam domain $e$ commerce. Hal ini juga mendukung penelitian dari Pinho, Martins, \& Macedo (2011) EService Quality berpengaruh sangat positif terhadap penggunaan system web. Hasil penelitian dari Firdausy \& Idawati (2017), Irawan (2018) dan Isnain Putra Baskara \& Guruh Taufan (2012), Kusumah Negara (2015) E-Service Quality memiliki dampak positif dan signifikan terhadap keputusan pembelian online. Sehingga secara keseluruhan dapat disimpulkan bahwa E-Service Quality dapat mempengaruhi keputusan penggunaan Aplikasi OVO.

Layanan yang dimiliki OVO juga sangat lengkap seperti onsite dining, offline retail, offline groceries, online marketplace, food delivery, online transportation, telecom topups, utilities, investment, dan fund transfer. Jadi pengguna tidak hanya bisa melakukan transaksi di restoran/cafe merchantnya OVO tetapi mereka dapat melakukan berbagai macam transaksi yang dibutuhkan hanya dengan menggunakan Aplikasi OVO. Didukung oleh jumlah merchant OVO yang mencapai 500.000 dan tersedia di 303 kota di Indonesia 
sehingga pengguna dapat melakukan transaksi menggunakan Aplikasi OVO dengan mudah. Hasil statistik menunjukkan bahwa item pernyataan yang memperoleh nilai mean tertinggi adalah item pernyataan $\mathrm{X}_{2.4 .3}$ menyatakan jika Aplikasi OVO memungkinkan saya untuk melanjutkan penggunaan saya dengan mudah”. Yang artinya Konsumen setuju jika mereka merasa aman dalam transaksi menggunakan Aplikasi ini dan memungkinkan mereka untuk menyelesaikan transaksi dengan cepat. Konsumen merasa mudah dalam menggunakan Aplikasi OVO dengan menggunakannya tanpa banyak usaha, mudah bergerak di antara halaman, dan kemudahan navigasi dalam suatu halaman.

\section{KESIMPULAN DAN SARAN}

\section{Kesimpulan}

Berdasarkan hasil penelitian dan pembahasan, maka dapat ditarik kesimpulan sebagai berikut: 1). Terdapat pengaruh promosi penjualan terhadap keputusan penggunaan aplikasi OVO. Hal ini dapat dibuktikan dari hasil analisis regresi yang menunjukkan tingkat signifikan sebesar 0,000 yang berada di bawah batas maksimum toleransi kesalahan, yaitu 0,005. Dengan demikian $\mathrm{H}_{1}$ didukung oleh data dan hasil ini mendukung hipotesis awal peneliti yang diajukan dalam penelitian. 2). Terdapat pengaruh E-Service Quality terhadap keputusan penggunaan aplikasi OVO. Hal ini dapat dibuktikan dari hasil analisis regresi yang menunjukkan tingkat signifikan sebesar 0,000 yang berada di bawah batas maksimum toleransi kesalahan, yaitu 0,005. Dengan demikian $\mathrm{H}_{2}$ didukung oleh data dan hasil ini mendukung hipotesis awal peneliti yang diajukan dalam penelitian.

\section{Saran}

Berdasarkan hasil penelitian dan pembahasan, maka dapat ditarik kesimpulan sebagai berikut: 1). Bagi Perusahaan: Untuk perusahaan disarankan untuk terus memperbaiki E-Service Quality yang benar-benar bisa bersaing dengan E-Payment yang lain. Memperluas layanan pembayaran di berbagai kebutuhan saat ini untuk dapat menarik lebih banyak konsumen agar beralih menggunakan Aplikasi OVO. Meskipun OVO merupakan platform pembayaran yang belum lama beroperasi tetapi tetap harus mampu memahami keadaan pasar yang terupdate untuk mengetahui kebutuhan apa yang sedang dicari dan diinginkan kebanyakan konsumen. Dengan itu, OVO akan mampu 
bersaing ketat untuk tetap eksis dalam memperluas pangsa pasarnya. 2). Bagi Peneliti Selanjutnya : Penelitian ini khususkan untuk pengguna OVO yang melakukan transaksi di restoran/cafe merchantnya OVO, sehingga disarankan untuk peneliti selanjutnya melakukan penelitian yang dapat mencakup lebih luas lagi pengguna OVO. Dengan lebih banyak responden pula agar hasil dari penelitian juga dapat mencakup bermacam-macam pengguna OVO dengan persepsi mereka masing-masing mengenai OVO.

\section{DAFTAR PUSTAKA}

A.Parasuraman, Valarie A.Zeithaml, A. M. (2005). A Multiple-Item Scale for Assessing Electronic Service $\quad$ Quality, $2(3), \quad 213-233$. https://doi.org/10.1177/1094670504271156

Beheshti, F., Shoki, M., \& Jusoh, A. (2012). E-Service Quality Dimensions and Their Effects on E- Customer Satisfaction in Internet Banking Services, 40, 441-445. https://doi.org/10.1016/j.sbspro.2012.03.213

Charles k. Ayo Aderonke Atinuke Oni Oyerinde J. Adewoye Ibukun O. Eweoya. (2016). E-banking users' behaviour: e-service quality, attitude, and customer satisfaction. International Journal of Bank Marketing, Vol. 34(Iss 3 pp), 23. Retrieved from http://dx.doi.org/10.1108/IJBM-12-2014-0175

Childers, T. L., Carr, C. L., Peck, J., \& Carson, S. (2001). Hedonic and utilitarian motivations for online retail shopping behavior, 77, 511-535.

Darko, E. (2012). The Influence Of Sales Promotion on Consumer Buying Behaviour in The Telecom Industry; The Case of Vodafone Ghana., (Pg 4107210).

Efraim Turban David King Jae Kyu Lee Ting-Peng Liang Deborrah C. Turban. (2015). Electronic Commerce A Managerial and Social Networks Perspective. EXTRAMATERIALSspringerlink.com (Eighth Edi). USA: springer. Retrieved from https://www.investopedia.com/terms/e/ecommerce.asp

Firdausy, C. M., \& Idawati, R. (2017). Effects of Service Quality , Price and Promotion on Customers ' Purchase Decision of Traveloka Online Airline Tickets in Jakarta, 
Jurnal Riset Manajemen Sains Indonesia (JRMSI) | Vol 11, No. 2, 2020

http://doi.org/10.21009/JRMSI

Indonesia, $\quad 3(2), \quad 42-49 . \quad$ https://doi.org/10.18775/ijmsba.1849-56645419.2014.32.1004

Ghozali, I. (2016). Aplikasi Analisis Multivariete Dengan Program IBM SPSS 23 (edisi 8). Semarang: Badan Penerbit Universitas Diponegoro.

Hanaysha, J. R. (2018). An examination of the factors affecting consumer's purchase decision in the Malaysian retail market. PSU Research Review. https://doi.org/10.1108/prr-08-2017-0034

Hulya Bakırtas. (2013). Impact of sales promotion on purchase decision of consumers : An application in tourism sector.

Irawan, I. A. (2018). Effect Of Trust, Convinience, Security And Quality Of Service On Online Purchase Decision ( Consumer Case Study In Tangerang Selatan Area ), XXIII(01), 114-122.

Isnain Putra Baskara, Guruh Taufan Hariyadi, SE, M. K. (2012). Analisis Pengaruh Kepercayaa, Keamanan, Kualitas Pelayanan, dan Persepsi Resiko Terhadap Keputusan Pembelian Melalui Situs Jejaring Sosial (Social Networking Websites), (2011), 1-15.

Jamaludin, Achmad, Z. A. K. H. (2015). Pengaruh Promosi Online dan Persepsi harga terhadap Keputusan Pembelian, 21(1).

Karimi, S., Papamichail, K. N., \& Holland, C. P. (2015). The effect of prior knowledge and decision making style on the online purchase decision making process : A typology of consumer shopping behaviour. Decision Support Systems. https://doi.org/10.1016/j.dss.2015.06.004

Kim, D. J., Ferrin, D. L., \& Rao, H. R. (2008). A trust-based consumer decision-making model in electronic commerce: The role of trust, perceived risk, and their antecedents. Decision Support Systems, 44(2), 544-564. https://doi.org/10.1016/j.dss.2007.07.001

Kotler, P., Bowen, J. T., \& Makens, J. C. (2014). Marketing for Hospitality and Tourism (kelima). New Jersey: Pearson Prentice Hall. 
Maftukhah, I., Rahmawati, F. D., \& Fadlilah, A. (2018). Considering the Influence of Digital Promotion Performed By Go-Jek Indonesia and C2C Marketplaces on Buyers ' Purchasing Decision, 2018, 541-552. https://doi.org/10.18502/kss.v3i10.3155

Malhotra, N. K. (2009), riset pemasaran (jilid 1). Jakarta: PT INDEKS.

Nagadeepa, C., Selvi, J. T., \& Pushpa, A. (2015). Impact o f Sale Promotion Techniques on Consu mers ' Impulse Buyıng Behaviour towards Apparels a t Bangalore, 4(January), 116-124.

Natalia, P., \& Mulyana, M. (2014). Pengaruh Periklanan Dan Promosi Penjualan Terhadap Keputusan Pembelian. Pengaruh Periklanan Dan Promosi Penjualan Terhadap Keputusan Pembelian, 2(2), 119-128. https://doi.org/2337-7860

Ni Wayan Nonik Ismayanti, I. W. S. \& I. M. K. N. (2015). Pengaruh Kepercayaan dan Eservie quality Terhadap Keputusan Pembelian Akomodasi di Bali pada Situs Booking.com, 3(1), 56-61.

Penia Anggraeni \& Putu Nina. (2016). The Effect of Trust and Information Quality to Online Purchase Decision on The site www.traveloka.com, 3(2), 1880-1887.

Pinho, J. C., Martins, M. D. L., \& Macedo, I. (2011). The effect of online service quality factors on internet usage The web delivery system of the taxation. https://doi.org/10.1108/02656711111150805

Razati, G. (2008). ( Survei Pada Dosen FPIPS UPI Pengguna Kartu kredit BNI’ 46 ) Abstrak.

Riyadi, Andy Putra, Mahkota Imam, S. (2014). Pengaruh Kepercayaan dan Kenyamanan Terhadap Keputusan Pembelian Online, 8(2).

Rolland, S., \& Freeman, I. (2010). A new measure of e-service quality in France. https://doi.org/10.1108/09590551011052106

Sheng, T. (2010). An empirical study on the effect of e-service quality on online customer satisfaction and loyalty. https://doi.org/10.1108/20408741011069205 
Jurnal Riset Manajemen Sains Indonesia (JRMSI) | Vol 11, No. 2, 2020

http://doi.org/10.21009/JRMSI

Silalahi, S. L. B., Handayani, P. W., \& Munajat, Q. (2018). ScienceDirect Service Quality Analysis for Online Transportation Services: Case Study of GO-JEK. Procedia Computer Science, 124, 487-495. https://doi.org/10.1016/j.procs.2017.12.181

Wolfinbarger, M., \& Gilly, M. C. (2003). eTailQ: dimensionalizing , measuring and predicting etail quality, 79, 183-198. https://doi.org/10.1016/S0022-4359(03)00034-4

Ye, L. R. (2014). Sales Promotion and Purchasing Intention: Applying the Technology Acceptance Model in Consumer-to-Consumer Marketplaces, 4(3), 1-5. 